\title{
Research on strategy management of supply chain 's response time compression \\ Wang Haiyuan
}

Department of economics and engineerings, Xijing University, Xi'an, 710123, China

Keywords: logistics management, rapid response, time compression

\begin{abstract}
Due to the breaking into the logistics industry of all the various trades and occupations, logistics industry develops too fast but ignores the construction itself, so make the logistics enterprise management problems become a bottleneck of the good development of obstacles. The ability of fast response to changes in market demand is one of the main sources of competitive advantage. The enterprises should compress the response time of the supply chain, let the whole supply chain to achieve the optimization and the enterprise to obtain the maximum benefit. In this paper we analyzed the influence factors of the supply chain and explored the methods to shorten the supply chain response time. This provides a good guide in the compressing the supply chain response time for other enterprises.
\end{abstract}

\section{Introduction}

Logistics enterprise management, as well as other enterprise management, is a common labor in a certain level of productivity and production relations. It reflects the nature of the objective requirement of the common labor and productivity, is in relation to the common needs of enterprise owners, operators and laborers, reflects the nature of the production relations, thus it has duality.

\section{The problems existing in the development of logistics enterprises in our country}

The enterprise management concepts are backward. The backward idea has two aspects performance: the first one is the lack of attention to the logistics industry. Currently, although many enterprise attaches great importance to the logistics problems! But only a few truly realize that the efficient logistics enterprise logistics management is market operation to improve logistics enterprises to save resources, reduce costs, improve the efficiency, is "the third profits source" of the enterprise. Now the logistics enterprises has not enough understand of logistics, just at the primary stage, only through the understanding of the theory and practice of international logistics information, don't realize that it is the need of the enterprise, so now the logistics enterprises is in a passive state. The second one is the lack of understanding of modern logistics. At present, in terms of most enterprises, the understanding of logistics is still in the traditional logistics category, think that logistics is just the entity flow process the goods from the supplier to accept.

The logistics enterprise management system has constraints and is lack of management talent. The development of logistics industry in China was conducted under the background of the transformation of old and new system, the personnel quality is low, there is no modern service concept, so inevitably influenced by the old system and at the same time the enterprise logistics development is likely to make original on-the-job lose the personnel work, in the current social security and employment system, enterprises are reluctant to adopt the mode of modern logistics management, and use the traditional management pattern.

\section{Management concepts of supply chain time}

At present, there are many concepts about the supply chain time. These concepts can be summarized in two aspects: the time concept of involved in the local operation of supply chain, such as design time, procurement, manufacturing, assembly time, distribution of time; On the other hand is reflect the responsive time concept, concepts such as supply chain response time, the time of 
delivery.

And the time in the supply chain management can also be to understand from the other two angles. As shown in the above, from the perspective of external customer expectations the shortest order response time, which is from order to receive the goods of all time, according to different types of production, the order response time is different too. From the internal view, time is a kind of resources that are consumed in the process. The supply chain can be divided into product design, procurement, manufacturing, assembly, distribution and so on several parts. And the time of the supply chain also produced by several links time and the cohesion between these processes.

Only to achieve agile on the overall process of supply chain , can quickly react to external demand. According to the research, value-added time is less than $5 \%$ in the whole supply chain process, eliminate waste time can not only improve the production efficiency, but also can greatly improve the response speed to customers. In addition, the enterprise managing time for supply chain can reduce demand amplification effect, and alleviate the fluctuation of the supply chain. As a result, time of supply chain management is required that each process time is compressed in the supply chain, to optimize supply chain as a whole, so as to make rapid response to needs of customer.

\section{Analysis on the influencing factors of supply chain response time}

With the development of supply chain management theory, advantage competitive between enterprises has gradually transferred from the competition to time. So all the companies focus on shortening the response time of supply chain, and to develop a suitable methods for their own enterprise supply chain management. Enterprises should first analyze the factors that affect the supply chain response time, further explore the methods to shorten the response time of supply chain.

Supply chain is a complex composed of many enterprises. Response time in supply chain is the result of joint action of many factors. Through the analysis of response time of factors in the supply chain, it can let us find a way to shorten the response time of supply chain. The main factors influencing the response time of supply chain are the supply chain information flow pattern, the partnership between enterprises, the structure of supply chain and supply chain facility location, etc.

1) Supply chain information flow.

In this information age, information flow has become the important factor of modern supply chain. In all the supply chain, logistics, cash flow are closely around the flow of information, only under the direction of information, logistics and cash flow is effective, can achieve the best efficiency and lowest cost. Manage the flow of information, in order to provide correct guidance for logistics and cash flow, to achieve the goal of supply chain management. Because the information flows directly affect the supply, production, distribution and other links of cohesion, if this cohesion is not good, it will produce a large number of invalid waiting time. If those links of the enterprise can do seamless connection, the assembly of the enterprise will be to a minimum. In this information age, many enterprises spent more than $50 \%$ of the time on processing the order relevant information, and only a small percentage of time is used for the supply, production, distribution, etc. Thus, we can know the importance of information flow in shortening the response time of supply chain.

2) The partnership between enterprises.

Supply chain is a complex composed of many enterprises. There are many nodes enterprise on a supply chain, and enterprise exists in the supply chain have partnership. Partnership refers to that the enterprises in the supply chain in order to meet the requirements of the final customer to achieve a certain period of mutual cooperation agreement. It provides that enterprises should to share information period, risk, remuneration, etc with each other in a certain time. The partnership between enterprises will make the response time of supply chain extension. It mainly displays in selecting suppliers, negotiation. Today with the developed of communication and transportation, the closer partnership between enterprises is, the shorter its supply chain response time will be. We can find that, the partnership between enterprises is an important factor to shorten the response time of supply chain. 
3) Product supply chain management

When some personalized needs produce, it can pull the entire product supply chain operation. Supply chain constitutes a supply chain network consists by suppliers, manufacturers, distributors, retailers and logistics providers and consumers. A product operating time compression in the supply chain includes constitute the supply chain of each enterprise internal time compression and tight before supplier and tight time compression after suppliers. At present, the commonly used time compression technology is QR technology. For some businesses, products supply chain management is a good way to compress the time. This not only can compress the response time of supply chain, to share information between enterprises and also can understand the real demand of the customers, and can provide customers with personalized products or services.

\section{Methods of shortening the response time of supply chain.}

In the supply chain management, the enterprise faster provide more value to customers, it can improve customer satisfaction. Therefore, to shorten the response time to customer's requirement, become the important competitive factors in supply chain management. In the integration of the supply chain, by shortening the response time of supply chain, can speed up the turnover of products in supply chain, reduce the inventory of each link in the supply chain, improve the whole supply chain reaction speed, to build the core competitiveness of the enterprise. In the process of supply chain management, enterprises need through a variety of means to shorten the time of supply chain, realize the maximization of the value of the entire supply chain, so as to build their own core competitiveness. In the process of supply chain management, enterprise to shorten the response time of supply chain strategy mainly includes the following aspects:

The time compression of information flow.

In the traditional supply chain, information flow is from every link of the downstream to upstream in turn, each enterprise gets demand information from the corresponding downstream enterprises, the demand information is not only a lag, but is not true. The causes of this situation have two aspects:

(1) There exists a "bullwhip effect". "Bullwhip effect" refers to that there is no trust between the buyer and seller, to conceal the real intent and information, it is also unable to get the real demand information for the downstream enterprises. In this way, only the enterprises in the bottom of the supply chain can obtain the real needs of the market to the supply chain but other enterprises can only indirectly to the final market demand information. But the market demand information is delayed or distorted information, make enterprise cannot arrange production according to these information. For the upper reaches enterprise, as a result of the farther from the final customer , to demand information gained by the degree of delay and distortion degree become more serious.

(2) The demand information may take the downstream enterprises to consider their own safety stock, or is modified according to the results of the prediction, the upstream enterprise can't really know the market demand. In this case, the longer the order cycle is, the untrue the message will be.

In the information age, information flow is an important factor in supply chain management. Enterprise can use electronic data interchange (EDI) and bar code technology to compress the time of information flow, such as to compresses information low time, thus achieve the compression response time of supply chain. Let enterprise not only can understand the real demand of the customers, but also can let the enterprise fast response to customer needs.

The time compression in partnership.

The time compression in partnership is mainly refers to the cooperation between enterprises of transportation, inventory and so on a variety of optimization problems based on time, and supply chain coordination incentive, etc. In terms of procurement and transportation, to strengthen the enterprise's strategic cooperative relations, to speed up the turnover of funds, a just-in-time (JIT) procurement method can shorten the time of procurement and transportation. In terms of inventory, the enterprise by means of joint inventory management, eliminate the phenomenon of demand amplification. Incentives of supply chain coordination is refers to the supply chain contract within a reasonable arrangement, the entire supply chain through the information integration and resource 
sharing in order to reduce the cost of production and inventory costs, reduce the phenomenon of shortage, improve the service level, accelerate the response speed of the supply chain, each node enterprises to win more. Through the compression supply chain partnership time between enterprises can effectively shorten the time of supply chain.

Logistics time compression between enterprises.

To compress the logistics time between enterprises, can improve supply chain performance. Instead, it will appear that such as the production time become compression, but the distribution time is longer. Only each node enterprise active information sharing with upstream and downstream enterprises, mutual cooperation, can it achieve the balance of each link logistics time, realize the optimization of a supply chain.

The production management of time compression

When designing products, not only to consider the compression of a single product design and development cycle, but also how to optimize the variety of products in the production, distribution, distribution. Because the product design plays a key role to the logistics of time compression, a good product design adopts the design of product standardization, can significantly reduce the changes in the process of machining, thus saving a lot of time. At the same time, enterprises need to understand the logistics central unvalued process, thus can compress process redundancy of time. Product standardization production or reduce logistics central unvalued processes, which can shorten the response time of supply chain, get enterprise core competitiveness.

\section{Conclusion}

Through time compression in these aspects, make the enterprise can quickly response to customer demand, and let the product of each link can connect well and won't produce unnecessary waiting time. As the market competition as well as the increase of demand uncertainty, enterprises pay more and more attention to time. To shorten the product market response time can let the enterprise get more competitive.

\section{Acknowledgments}

The author wish to acknowledge the support of scientific research funds (XJKY20130210) of Xiing University in Shaanxi, China; Key projects(SK2016A0269) of Humanities and Social Sciences in Colleges and Universities of Anhui Province.

\section{References}

[1] Lin yong, Ma Shihua, Supply chain management [M]. Higher education press, 2006:2-7.

[2] Liu wei. Supply chain management [M]. Sichuan people's publishing house, 2002:160-172.

[3] Chen Tingbin, Eu Zeshu. Supply chain and logistics management [M]. Tsinghua university press, 2008:348-361.

[4] Xuzhang. The value of agile logistics, supply chain integration implementation [M]. China supplies press, 2004:144-155.

[5] Zhao Weichen. Supply chain cycle time management and compression. [J]. Journal of logistics technology, 2005, 29:24-26.

[6] Sun Yanlin. Time compression in supply chain management strategy [J]. Journal of transportation and logistics, 2006, 1:40 and 41.

[7] ChuYunHuan. Time compression in supply chain operation strategy analysis [J]. Journal of shaanxi institute of technology, 2004, 20:80-81.

[8] FuQiuFang, Wang Wenbo. Based on shorten the response time of the implementation of supply chain management system [J]. Journal of logistics technology, 2008, 27:190-191. 
[9] Shang Yang. Factors influencing the rapid response of the supply chain analysis [J]. Science and technology information. 2011, 5:681-682.

[10] Tan Hui, Ma Shihua. Time bottleneck of supply chain and value evaluation research [J]. Journal of industrial engineering and management, 2006, (3) : 1-3. 